\title{
Analysing Torque-slip Characteristic of a Small Power Induction Motor Operating under Geophysical Conditions
}

\author{
Pranas Smolskas ${ }^{1,3}$, Mykolas Zmuida ${ }^{2}$ \\ ${ }^{1}$ Department of Electric Power Systems, Kaunas University of Technology, \\ Studentu St. 48, LT-51367 Kaunas, Lithuania \\ ${ }^{2}$ Department of Graphics Drawing, Kaunas University of Technology, \\ Studentu St. 48, LT-51367 Kaunas, Lithuania \\ ${ }^{3}$ Department of Energetics and Electronics, Kaunas University of Applied Engineering Sciences, \\ Tvirtoves av. 35, LT-50155 Kaunas, Lithuania \\ pranas.smolskas@ktu.lt
}

\begin{abstract}
The article analyses the torque-slip characteristic of a small power induction motor up to $50 \mathrm{~W}$ used in mechatronic system drives of a borehole investigation devices, that works at a wide range of temperature (from $-20{ }^{\circ} \mathrm{C}$ to $+150{ }^{\circ} \mathrm{C}$ ) and is supplied through a long geophysical cable with complex impedance which changes from $\underline{\mathrm{Z}}_{\mathrm{C}}=(127.5-\mathrm{j} 1.8)$

to $\underline{z}_{\mathrm{c}}=(165-\mathbf{j} 2.9)$. The external diameter of the induction motor is up to $36 \mathrm{~mm}$, the number of stator teeth is 8 . The torque-slip characteristics have been calculated for different cases, when the stator winding is single-layer, two-layer shortpitch and sinusoidal, motor rotor is solid and copper-cage solid. The calculated torque-slip characteristics at environment temperature $+20{ }^{\circ} \mathrm{C}$ were compared with the tested performed experiments.
\end{abstract}

Index Terms-Cage solid rotor induction motor, stator winding, torque-slip characteristic.

\section{INTRODUCTION}

Considering the requirements for the special purpose small power induction motors (high mechanical and thermal resistance; motor working medium - dielectric fluid or air; high quality of starting characteristic; motor operation under a wide slip range as it does not have a fixed operating point and other specific requirements), the optimal criteria may be the corresponding functional characteristic. In this case, torque-slip characteristic considered as a functional characteristic. Therefore, the satisfaction of the requirements contradicts the energy parameters, which are set for traditional induction motors.

Special purpose induction motors operating under geophysical conditions were analysed in [1], [2]. At the beginning, induction motors (up to $150 \mathrm{~W}$ ) with solid rotor and supplied by single-core cable were designed for geophysical borehole research equipment, where the environment temperature rises up to $+2500^{\circ} \mathrm{C}$, and hydrostatic pressure happens up to $210 \mathrm{MPa}$ in [3]. More powerful cage-solid rotor induction motors were analysed in

Manuscript received 15 May, 2015; accepted 6 November, 2015.
[4], [5].

The development of geophysical equipment and its functions increase the requirements for the operation of electric motors used in various mechatronic system electric drives, when motors are supplied by limited power sources through long multi-core geophysical cables, their complex impedance reaches up to $165-\mathrm{j} 5$, and environment temperature - up to $+150^{\circ} \mathrm{C}$. The insulating high temperature resistant materials based on polypiromelitimyde and polytetrafluorethylene are used.

High environment temperature or other factors, e.g. contact loss between the ring and rods, may cause an accident. In case of a contact loss, the motor the copper-cage solid rotor will work almost as a solid rotor. Therefore, traditional induction motors with cage rotors are unacceptable due to insufficient rotor reliability.

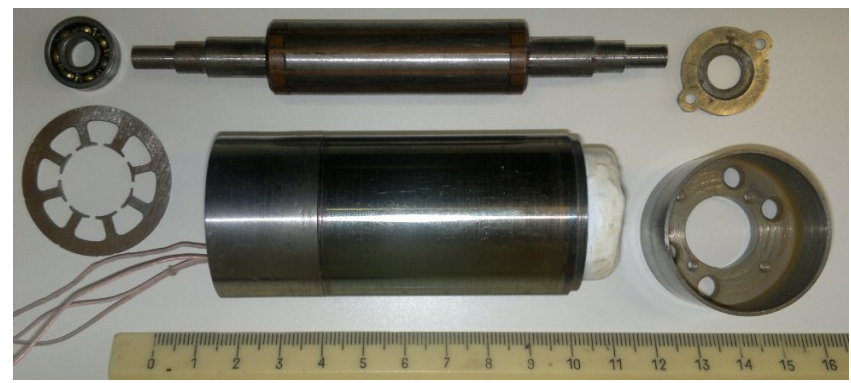

Fig. 1. The main components of the copper-cage solid rotor induction motor.

The goal of the work is to perform analysis of a torqueslip characteristics and to test experimentally of small power induction motor when it is made with solid rotor and cage solid rotor, the stator windings are made as two-layer shortpitch, sinusoidal and single-layer. The research is focused on a limited external diameter small power two-phase symmetrical induction motor, which has main parameters as: $36 \mathrm{~mm}$ external diameter, $50 \mathrm{~mm}$ active length, the number of stator slots ' 8 ', $17 \mathrm{~mm}$ internal stator diameter, $0.2 \mathrm{~mm}$ air gap and made by solid and copper-cage solid rotors. The one of motor with copper-cage solid rotor is shown in Fig. 1. 


\section{STATOR WINDING}

Single-layer winding is simpler manufactured, the slot is exploited more efficiently, but superior harmonics are highly expressed $(v=3,5,7,9$ here 7 and 9 are teeth harmonics of the first order). Two-layer winding is more complex in manufacturing, the slot is exploited worse, but the winding pitch may be shortened [6].

Sinusoidal two-phase winding $\left(2 \mathrm{p}=2, Z_{\mathrm{S}}=8\right)$ with concentric coil groups has to be produced two-layer, because one coil group corresponds to one pole. On the other hand, the slots of this sinusoidal winding will be filled equally, as well as the two-layer preformed short-pitch windings.

The harmonic factor $k_{w v}$ of sinusoidal winding is given in [7]. The equations below show a procedure to calculate the $v$-th harmonic factor of sinusoidal two-phase winding

$$
k_{u v}=\sum_{i=1}^{q} N_{s i} \sin \left(v y_{i} \frac{\alpha}{2}\right),
$$

where $q$ - number of slots per pole per phase; $N_{s i}-$ turn number of $i$ section; $y_{i}-$ pitch of $i$ section; $\alpha=\frac{\pi}{\tau}-\operatorname{slot}$ pitch expressed by the electrical degrees of the main space harmonic.

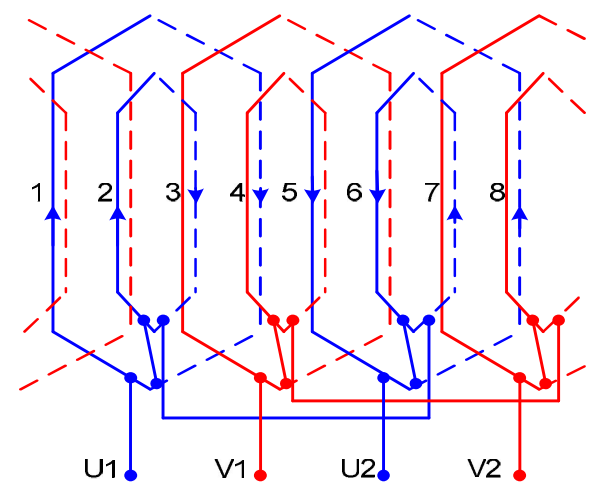

(a)

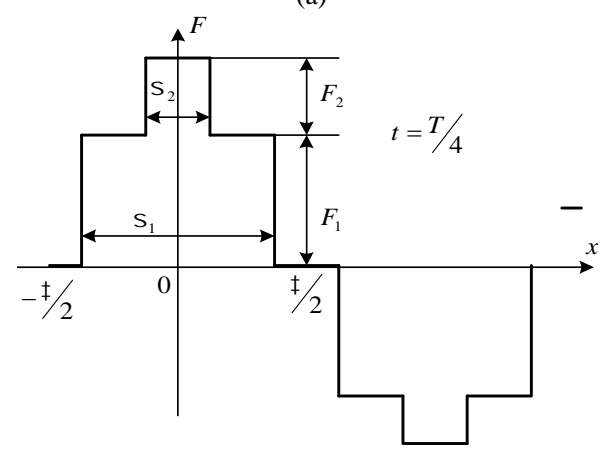

(b)

Fig. 2. Electric diagram of sinusoidal winding and space distribution of magnetomotive force developed by sinusoidal winding.

Because these windings $q=2$, so $N_{s 1}^{*}=\frac{\lambda_{1}}{\lambda_{\Sigma}}$, and $N_{s 2}^{*}=\frac{\lambda_{2}}{\lambda_{\Sigma}}$, here $\lambda_{1}=\sin \frac{\beta_{1}}{2}, \lambda_{2}=\sin \frac{\beta_{2}}{2}, \lambda_{\Sigma}=\lambda_{1}+\lambda_{2}$

(Fig. 2). Therefore the first harmonic $(v=1)$ of sinusoidal winding harmonic factor is

$$
k_{\mathrm{w} 1}=0.707 \sin \frac{3 \pi}{8}+0.293 \sin \frac{\pi}{8}=0.7653,
$$

and for higher harmonics $k_{\mathrm{w} 3}=-0.001395$, $k_{\mathrm{w} 5}=0.0001395, \quad k_{\mathrm{w} 7}=-0.7653, \quad k_{\mathrm{w} 9}=-0.7653$. While for two-layer windings accordingly $k_{\mathrm{w} 1}=0.8534$, $k_{\mathrm{w} 3}=-0.1464, \quad k_{\mathrm{w} 5}=0.1464, \quad k_{\mathrm{w} 7}=-0.8534$, $k_{\mathrm{w} 9}=0.8534$.

\section{ANALYSING OF TORQUE-SLIP CHARACTERISTIC}

The calculating of torque-slip characteristic performed for small power induction motor considering the temperature change of borehole medium and its effect to the motor and geophysical cable parameters by algorithm in [8]. The algorithm also evaluated the compatibility of motor and feed circuit parameters, saturation of motor magnetic circuit, rotor end effect, hysteresis losses and the higher space harmonics of the magnetic field. The main parameter of geophysical cable is complex impedance $\underline{Z}_{\mathrm{C}}$. Therefore, the geophysical cable is replaced by quadripole one, connected between the supply source and electric motor. Torque-slip characteristic was calculated as evaluating as 1, 3, 5, 7, 9 space harmonics.

The supply voltage of these motors in slip range $1-s_{0}$ changes approximately from $175 \mathrm{~V}$ to $200 \mathrm{~V}$ when rotor is cage solid and from $190 \mathrm{~V}$ to $215 \mathrm{~V}$ when rotor is solid ( $s_{0}$ is the no-load slip). Power supply voltage was chosen $240 \mathrm{~V}$ (it depends on the complex impedance of the supply circuit) because the motor operates under different environment temperatures from $-20^{\circ} \mathrm{C}$ to $+150^{\circ} \mathrm{C}$ and its torque-slip characteristics also changes even changing form a little. In order to avoid high changes of torque-slip characteristic, it is foreseen to change power supply voltage every $10 \mathrm{~V}$, and for capacitor motor - every $20 \mathrm{~V}$.

Usually the complex impedance $\underline{Z}_{\mathrm{C}}$ is set; it depends on the cable length, which is put into $e . g$. borehole, and on the environment temperature at the measurement point. The traditional design methods of the conventional cage rotor induction motors directly unfit for use of the borehole motors, because the fixed nominal operation point is not characteristic for them due to complicated specific working environment [1]. The factor $k_{\mathrm{M}}=\frac{P_{\mathrm{M}}}{P_{\mathrm{M} \max }}$ shows how effectively the supply circuit is exploited (here $P_{\mathrm{M}}$-input active motor power, $P_{\mathrm{Mmax}}-$ maximum transmitted active power to motor) [9]. $P_{\mathrm{Mmax}}$ would be maximum, if motor input impedance $\underline{Z}_{\mathrm{M}}$ is equal to conjugate value of cable output impedance $\underline{Z}_{\mathrm{C}}^{*}$. Difference $1-k_{\mathrm{M}}$ indicates the biggest part of electric loss that is lost in feed circuit.

Electromagnetic efficiency factor $k_{\text {ef }}$ indicates what part of the first harmonic relative rotational magnetomotive force remains after the compensation of negative effect of its higher harmonics [7]. For the sinusoidal winding, it is 0.775 
and is only $1.42 \%$ higher than of two-layer winding.

Table I presents the results of the analysed induction motor torque-slip characteristic: when power supply voltage is $240 \mathrm{~V}$; number of rotor teeth is $Z_{\mathrm{R}}=13$; slot dimensions are $h \times b=2,8 \times 1,8 \mathrm{~mm}$; *the dimensions of this rotor slot are $h \times b=2,0 \times 0,8 \mathrm{~mm}$.

It is convenient to evaluate torque-slip characteristics according to the electromagnetic torque average value $T_{\mathrm{em} . a v}$ (Table I) in the working slip range $1-s_{0}$ [9]

$$
T_{\text {em.av }}=\frac{1}{1-s_{0}} \int_{s_{0}}^{1} T_{\mathrm{em}}(s) \mathrm{d} s .
$$

In motors with two-layer and sinusoidal windings (Table I, Table II and Fig. 3, Fig. 4), when rotor is cage solid (power supply is two-phase symmetrical) torque-slip characteristics do not differ more than $5 \%$. The electromagnetic torques created by the first harmonics differs up to $7 \%$. Torque-slip characteristic is more advantageous when stator winding is sinusoidal, because the electromagnetic torques created by higher harmonics is much smaller than stator winding is two-layer. (Table I, Fig. 4). Winding factors affect the rotor's active resistance, inductive reactance and reactance of mutual induction values.

TABLE I. COMPUTED PARAMETERS.

\begin{tabular}{|c|c|c|c|c|c|c|}
\hline \multicolumn{7}{|c|}{ Two-phase symmetrical power supply } \\
\hline Stator winding & $\begin{array}{l}\text { Rotor } \\
\text { type }\end{array}$ & $\begin{array}{c}T_{\text {em, av }} \\
\mathrm{N} \cdot \mathrm{m}\end{array}$ & $\begin{array}{c}T_{\mathrm{em}}\left(s_{c}\right) \\
\mathrm{N} \cdot \mathrm{m}\end{array}$ & $s_{\mathrm{c}}$ & $s_{\mathrm{o}}$ & $k_{\mathrm{M}}$ \\
\hline \multirow{2}{*}{$\begin{array}{c}\text { Two-layer } \\
\text { former short } \\
\text { pitch } y=3\end{array}$} & \multirow{2}{*}{$\begin{array}{l}\text { Cage } \\
\text { solid } \\
\text { rotor }\end{array}$} & 0.131 & 0.154 & 0.353 & 0.024 & 0.743 \\
\hline & & 0.091 & 0.109 & 1.140 & 0.029 & 0.703 \\
\hline \multirow{2}{*}{$\begin{array}{c}\text { Two-layer } \\
\text { former short } \\
\text { pitch } y=3\end{array}$} & \multirow{2}{*}{$\begin{array}{l}\text { Solid } \\
\text { rotor }\end{array}$} & 0.078 & 0.122 & 1.142 & 0.038 & 0.765 \\
\hline & & $\overline{0.041}$ & $\overline{0.066}$ & $\overline{1.145}$ & $\overline{0.032}$ & 0.703 \\
\hline \multirow{2}{*}{$\begin{array}{c}\text { Sinusoidal } \\
y=3, y=1\end{array}$} & \multirow{2}{*}{$\begin{array}{l}\text { Cage } \\
\text { solid } \\
\text { rotor }\end{array}$} & $\underline{0.132}$ & $\underline{0.159}$ & $\underline{0.321}$ & $\underline{0.013}$ & 0.363 \\
\hline & & $\overline{0.090}$ & $\overline{0.103}$ & 0,475 & $\overline{0.017}$ & 0.390 \\
\hline \multirow{2}{*}{$\begin{array}{c}\text { Sinusoidal } \\
y=3, y=1\end{array}$} & \multirow{2}{*}{$\begin{array}{l}\text { Solid } \\
\text { rotor }\end{array}$} & 0.079 & 0.123 & 1.143 & 0.002 & 0.412 \\
\hline & & $\overline{0.039}$ & $\overline{0.065}$ & $\overline{1.142}$ & 0.0017 & 0.452 \\
\hline \multicolumn{7}{|c|}{ Single-phase power supply, $C_{\mathrm{w}}=4 \mathrm{~F}$} \\
\hline \multirow{2}{*}{$\begin{array}{c}\text { Two-layer } \\
\text { former short } \\
\text { pitch } y=3\end{array}$} & \multirow{2}{*}{$\begin{array}{l}{ }^{*} \text { Cage } \\
\text { solid } \\
\text { rotor }\end{array}$} & 0.089 & 0.099 & 0.450 & 0.051 & 0.798 \\
\hline & & 0.078 & 0.091 & 0.672 & $\overline{0.052}$ & 0.777 \\
\hline \multirow{2}{*}{$\begin{array}{c}\text { Sinusoidal } \\
y=3, y=1\end{array}$} & \multirow{2}{*}{$\begin{array}{l}\text { Cage } \\
\text { solid } \\
\text { rotor }\end{array}$} & 0.0698 & 0.0955 & 0,225 & 0.0141 & 0.838 \\
\hline & & 0.0595 & $\overline{0.0718}$ & 0,329 & 0.0164 & 0.828 \\
\hline \multirow{2}{*}{$\begin{array}{c}\text { Single-layer } \\
\text { concentric } \\
y=4\end{array}$} & \multirow{2}{*}{$\begin{array}{l}\text { Cage } \\
\text { solid } \\
\text { rotor }\end{array}$} & $\underline{0.067}$ & $\underline{0.083}$ & $\underline{0,268}$ & $\underline{0.043}$ & $\underline{0.790}$ \\
\hline & & 0.065 & $\overline{0.074}$ & 1,111 & 0.048 & 0.795 \\
\hline
\end{tabular}

Note: in numerator - when environment temperature is $+20^{\circ} \mathrm{C}$; cable complex impedance $\underline{Z}_{\mathrm{C}}=(127.5-\mathrm{j} 1.8) \quad$; in denominator - when environment temperature is $+150^{\circ} \mathrm{C}$; cable complex impedance $\underline{Z}_{\mathrm{C}}=(165-\mathrm{j} 2.9)$.

If the motor rotor is solid, the torque-slip characteristics are similar when environment temperature is either $+20^{\circ} \mathrm{C}$ or $+150^{\circ} \mathrm{C}$ according to the computed results (Table I) and according to their form (Fig. 5). When power is supplied from a single-phase network, the most rational torque-slip characteristic according to the form and parameters (Table I) is of motor with two-layer winding (*age solid rotor slot measurements are $h \times b=2,0 \times 0,8 \mathrm{~mm}$ ).

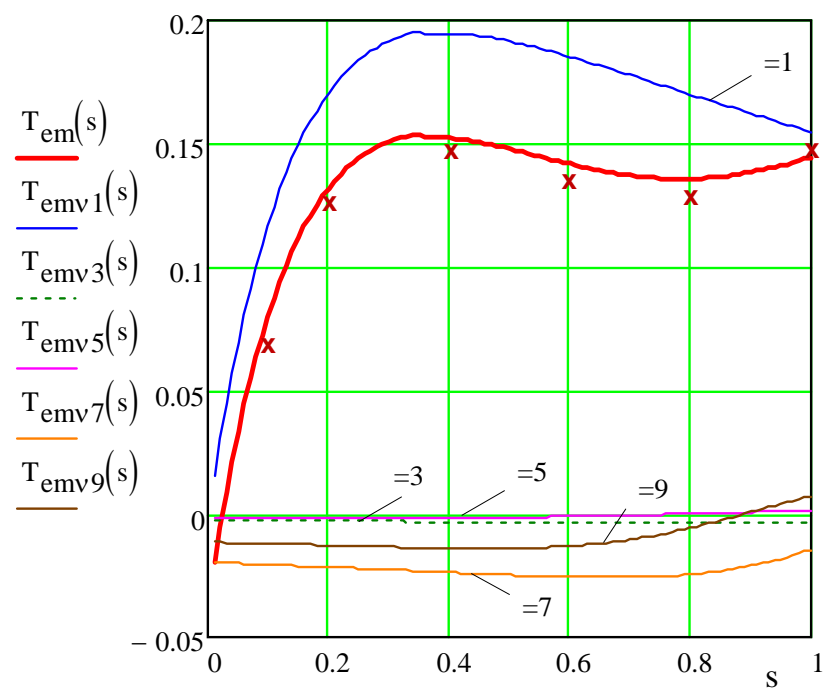

Fig. 3. Calculated and measured torque versus slip characteristics (computed, solid lines; measurement, dots; see TABLE II).

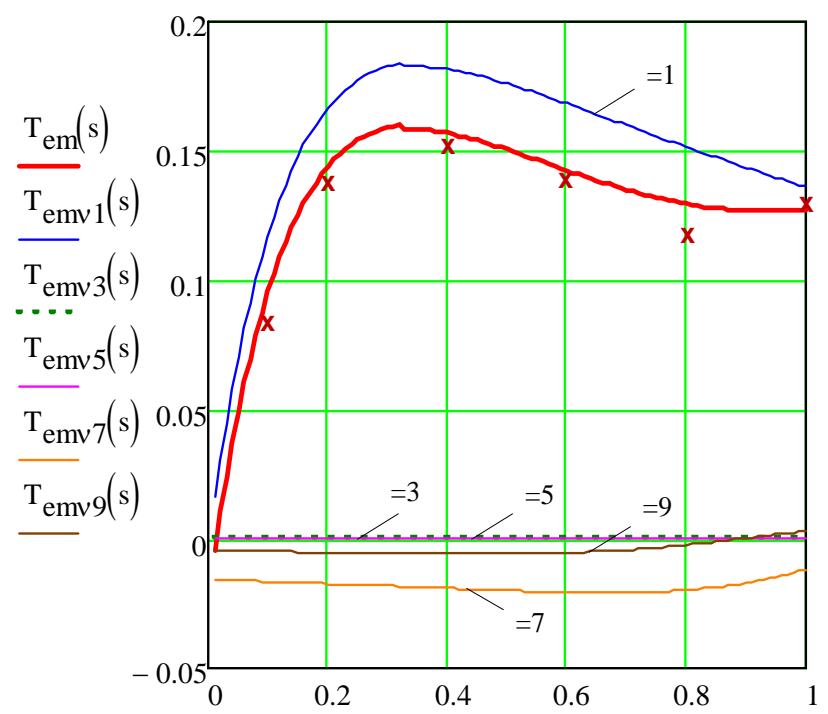

Fig. 4. Calculated and measured torque versus slip characteristics: (computed, solid lines; measurement, dots; see TABLE II).

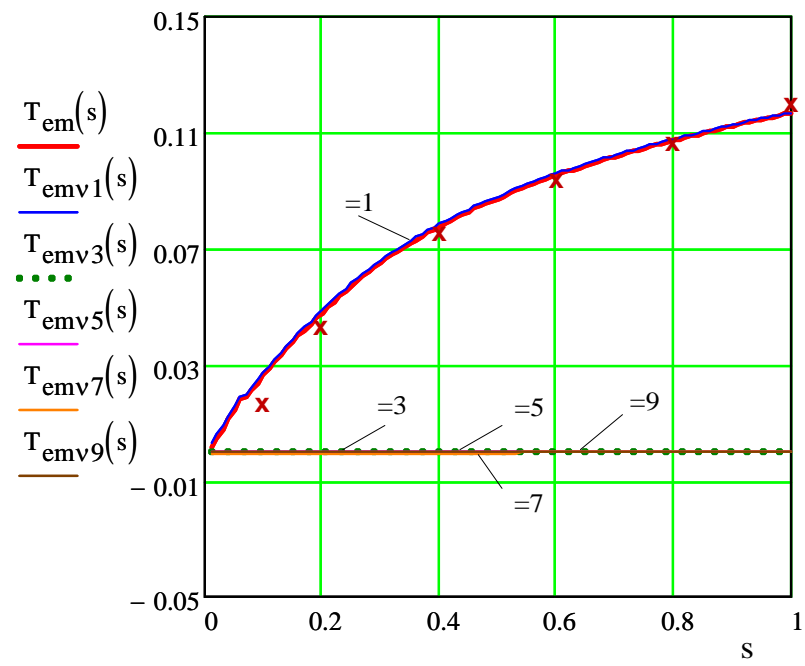

Fig. 5. Calculated and measured torque versus slip characteristics: (computed, solid lines; measurement, dots; see TABLE II). 


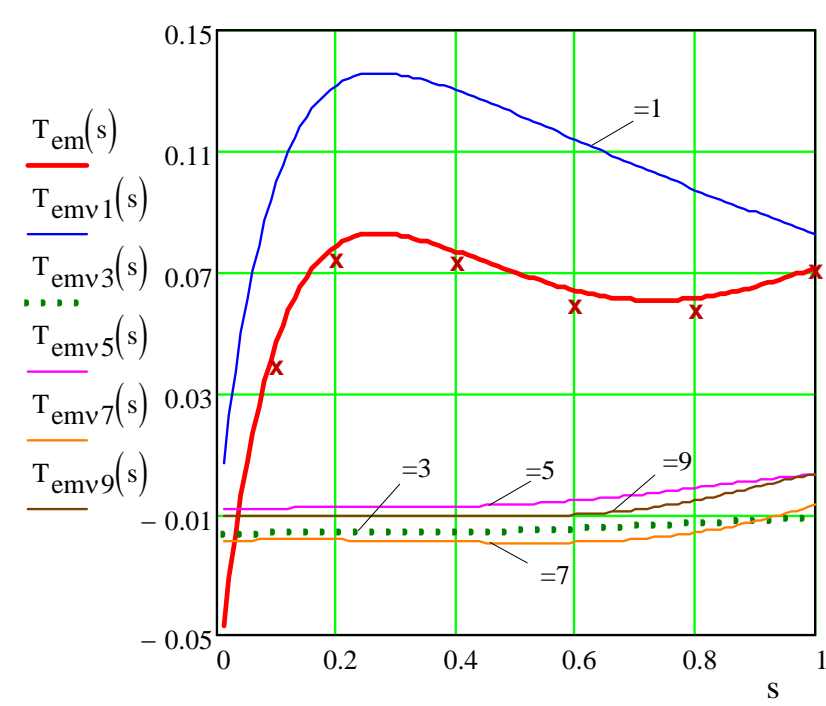

Fig. 6. Calculated and measured torque versus slip characteristics: (computed, solid lines; measurement, dots (see TABLE II)).

The torque-slip characteristic form of capacitor motor with cage-solid rotor is unacceptable (Fig. 6), because the starting torque is low, and electrical loss is high. When the cage winding resistance is increased, then torque-slip characteristic becomes more rational, starting torque is higher and $T_{\text {em..av }}$ is bigger. The biggest $T_{\text {em.av }}$ value is when the running capacitor's capacity is $4 \mathrm{~F}$. This is valid for motor stator with winding of the analysed type. If the running capacitor's capacity is $3 \mathrm{~F}, T_{\text {em..av }}$ decreases to $8 \%$, when it is $5 \mathrm{~F}-$ to $2 \%$.

\section{EXPERIMENTAL RESEARCH}

Active resistance of stator winding phase: two-layer windings -225 , sinusoidal -232 , single-layer -258 . Turn numbers of stator winding phase - two-layer and sinusoidal -1100 , single-layer 1200 . Numbers of rotor teeth are 13, slots are rectangular. The cable was replaced by equivalent scheme (which was formed of resistances and capacitors) so that $1 \mathrm{~km}$ corresponds to 25.5 , and the capacity between cable core and armor or between the cores is $0.25 \mathrm{~F}$ (when cable is multi-core, three-core cable was simulated). The experiment carried out under the temperature $+20^{\circ} \mathrm{C}$. Resistance of power supply scheme was $\underline{Z}_{\mathrm{C}}=(127-\mathrm{j} 1.8) \quad$. Two perpendicular voltages (twophase symmetrical) were made applying Scott-connected transformer, voltage values were regulated by single-phase laboratory autotransformers. Torque measurement points were fixed and deduced corresponding slip values 1.0, 0.8, $0.6,0.4,0.2,0.1$ (Table II).

The tested motor was vertically fixed between the rotating torquemeter centres. The lower centre was connected to the rotating drive motor, which rotation speed was smoothly controlled from $n=0$ to $n=3500 \mathrm{~min}^{-1}$. The motor's frame is its external diameter too. A central ring was attached to the frame; the ring was reinforced with the torque (force) pick-up. Force was measured with strain-gauge transducer. The rotation speed was measured with "testo 465".
During the test, the stator winding temperature (at each slip point) was maintained $+20^{\circ} \mathrm{C}$. After every deduction, the voltage was turn off; motor was cooled with an additional ventilator. The temperature was controlled by measuring the stator winding's active resistance.

TABLE II. CALCULATED AND MEASURED TORQUE VALUES AT SLIP VALUES AS ENVIRONMENT TEMPERATURE $+20^{\circ} \mathrm{C}$

\begin{tabular}{|c|c|c|c|c|c|c|}
\hline $\begin{array}{c}T_{\text {em }}(1) \\
\text { N.m }\end{array}$ & $\begin{array}{c}T_{\text {em }}(0.8) \\
\text { N.m }\end{array}$ & $\begin{array}{c}T_{\text {em }}(0.6) \\
\text { N.m }\end{array}$ & $\begin{array}{c}T_{\text {em }}(0.4) \\
\text { N.m }\end{array}$ & $\begin{array}{c}T_{\text {em }}(0.2) \\
\text { N.m }\end{array}$ & $\begin{array}{c}T_{\text {em }}(0.1) \\
\text { N.m }\end{array}$ & $s_{\text {o }}$ \\
\hline Two-layer short pitch winding, cage solid rotor, two-phase symmetrical \\
power supply (Fig. 3)
\end{tabular}

Note: Upper row - computed values; lower row - measured values.

\section{CONCLUSIONS}

According to the presented analysis results of torque-slip characteristic, it is possible to choose the induction motor for the special purpose drives operating under geophysical conditions considering the supply circuit parameters. The analysis of the torque-slip characteristic of the investigated motor was performed in different cases i.e. replacing one-byone the laid out stator winding, when the made rotor was copper-cage solid and solid (Table I).

When the motor is supplied from single-phase power source, and the stator winding is sinusoidal, the best results are obtained. But, in order to synchronize the total rotor active resistance with the power cable circuit active resistance, the rotor slots are reduced (slot diameter up to 3 times). The use of single-layer winding is not purposeful because of the significant effect of the third harmonic. As the environment temperature increases the torque-slip characteristic's form changes due to relatively small influence of higher harmonic. The torque-slip characteristic is more advantageous when stator winding is sinusoidal and rotor is copper-cage solid.

Torque-slip characteristic's electromagnetic torque values that are computed by the motor and are experimentally set do not vary more than $10 \%$ in the slip range $s=1-0.25$, but when slip range values are smaller $s<0.25$, then torque values differ more than $10 \%$.

The analysis of characteristics in much the same way can be put in practice for other size motors with smaller external diameters (e.c. $31 \mathrm{~mm}, 25 \mathrm{~mm}$ ) and different parameters of the supply circuit.

\section{REFERENCES}

[1] S. Gecys, S. Gudzius, A. Morkvenas, "The Influence of complex supply circuit parameters on electrical motors characteristics for borehole investigating devices", in Proc. of the XIII Int. Conf. on Electromagnetic Disturbances, (EMD 2003), Bialystoc, Poland, 
2004, pp. 229-232.

[2] S. Gecys, "An influence of operating medium temperature change on characteristics of electric motor for borehole investigating devices", Elektronika ir Elektrotechnika, no. 1, pp. 64-67, 2006.

[3] S. Gecys, S. Gudzius, L. Markevicius, A. Morkvenas, "Critical slip and maximum electromagnetic power of a motor for borehole prospecting mechatronic devices", Solid State Phenomena, vol. 113 pp 55-60, 2006. [Online]. Available: http://dx.doi.org/10.4028/ www.scientific.net/SSP.113.55

[4] . ербовой, . ербовой, . ъянов, “ ин мические $\mathrm{x}$ р ктеристики синхронного двиг теля с м ссивным ферром гнитным ротором и короткоз мкнутой обмоткой”, Unconventional electromechanical and electrotechnical systems, pp. 397-400, 1996. (in Russian).

[5] M. Valtonen, A. Parviainen, J. Pyrhonen, "The effects of the number of rotor slots on the performance characteristics of axial-flux aluminum-cage solid-rotor core induction motor", IEEE Int. Conf. on Electric Machines \& Drives, (IEMDC 2007), vol. 1, pp.668-672, 2007.

[6] . . опухин, . . еменчуков, втом тизиров нное проектиров ние электрических м шин м лой мощности, $\therefore$ ысш я школ , 2002, 512 с. (in Russian).

[7] J. Buksnaitis, Kintamosios srov s trifaziu elektros mašinu apviju elektromagnetinis efektyvumas. Kaunas: Technologija, 2007, 196 p.

[8] S. Gecys, P. Smolskas. "Small-power capacitor copper-cage solid rotor induction motor for borehole investigation devices", in Proc. of the XVIII Int. Conf. on Electromagnetic Disturbances, (EMD 2008), 2008, pp. 53-56.

[9] S. Gecys, P. Smolskas, "Parametrical optimization of equivalent circuit parameters of copper-squirrel-cage solid rotor induction motor supplied through long geophysical cable", Elektronika ir Elektrotechnika, no. 2, pp. 73-76, 2009. 